\title{
MASSA SECA E MACRONUTRIENTES ACUMULADOS EM PLANTAS DE MILHO CULTIVADAS SOB DIFERENTES ESPÉCIES DE COBERTURA
}

\author{
SILVINO GUIMARÃES MOREIRA ${ }^{1}$, RENATA MOTA LUPP ${ }^{1}$, CARINA GARCIA DE LIMA ${ }^{1}$, \\ ROSANGELA CRISTINA MARUCCI ${ }^{2}$, ÁLVARO VILELA DE RESENDE ${ }^{3}$ e IRAN DIAS BORGES ${ }^{1}$
}

${ }^{1}$ UFSJ, SeteLagoas,MG,Brasil,silvino@ufsj.edu.br,idb@ufsj.edu.br,lupp.ufsj@ymail.com,carinagarcialima@yahoo.com.br ${ }^{2}$ Unifemm, Sete Lagoas, MG, Brasil, rosangela.marucci@rehagro.com.br

${ }^{3}$ Embrapa Milho e Sorgo, Sete Lagoas, MG, Brasil, alvaro.resende@embrapa.br

Revista Brasileira de Milho e Sorgo, v.13, n.2, p. 218-231, 2014

\begin{abstract}
RESUMO - Estudos sobre plantas de cobertura de solo, em áreas de milho para silagem, são raros no Brasil e aqueles que abordam o efeito dessas plantas na nutrição do milho são ainda mais escassos. Objetivou-se avaliar o efeito de diferentes plantas de cobertura na produtividade de massa seca (MS) e no acúmulo de macronutrientes na parte aérea da planta de milho (espigas, folhas, colmos). O trabalho foi realizado na Fazenda Santo Antônio, em Matozinhos, MG. O delineamento experimental foi o de blocos ao acaso, com quatro repetições e nove tratamentos, sendo oito espécies de cobertura - nabo forrageiro (Raphanus sativus), milheto (Pennisetum americanum), Brachiaria ruzziziensis, B. decumbens, Crotalarea juncea, tremoço (Lupinus albus), aveia preta (Avena strigosa) e girassol (Helianthus annuus) - e uma área de pousio. A produtividade de MS da parte aérea do milho não foi modificada pelas plantas de cobertura. As concentrações dos macronutrientes nas plantas de milho não variaram devido aos tratamentos. Por sua vez, as quantidades totais de $\mathrm{Ca}$ e $\mathrm{S}$ nas plantas de milho foram modificadas. As quantidades acumuladas de macronutrientes nas espigas também não foram afetadas pelos tratamentos, com exceção das quantidades de $\mathrm{P}$ e Ca nas folhas e no colmo.
\end{abstract}

Palavras-chave: plantas de cobertura; silagem de milho; sucessão de culturas.

\section{DRY MATTER AND MACRONUTRIENTS ACCUMULATED IN MAIZE PLANTS CULTIVATED UNDER DIFFERENT COVER CROP SPECIES}

\begin{abstract}
Studies regarding cover crops in areas of maize for silage are scarce in Brazil, especially those focused on the effect of these plants on maize nutrition.. This study aimed at evaluating the effect of different cover crops on the dry matter (DM) yield and on the accumulation of macronutrients in maize plants (cobs, leaves, stalks). The study was conducted at Fazenda Santo Antônio, in Matozinhos, MG, Brazil. A randomized blocks design was used, with four replications and nine treatments being eight species of cover crops - Cultivated Radish (Raphanus sativus), Pearl Millet (Pennisetum americanum), Brachiaria ruzziziensis, B. decumbens, Crotalarea juncea, White Lupin (Lupinus albus), Black Oat (Avena strigosa) and Common Sunflower (Helianthus annuus) - and one area of fallow land. The DM yield of maize plants was not affected by the cover crops. In general, macronutrients concentration in maize plants were not affected by treatments. On the other hand, the total amount of $\mathrm{Ca}$ and $\mathrm{S}$ changed in maize plants.. The amounts of macronutrients accumulated in maize cobs were not affected, except for the amounts of $\mathrm{P}$ and $\mathrm{Ca}$ in the leaves and stalks.
\end{abstract}

Key words: cover crops; maize silage; crops succession. 
Nos últimos anos, houve grandes avanços no manejo da cultura de milho e, consequentemente, ganhos em produtividade em todo o país, devido à adoção de novas tecnologias, dentre elas o sistema de semeadura direta (SSD). Apesar disso, notoriamente em relação à adoção desse sistema, alguns desafios ainda precisam ser superados. Dentre eles, ainda há grandes dificuldades no estabelecimento das culturas de inverno, após a retirada do milho, nas regiões de inverno seco.

A região Central de Minas Gerais é uma das principais bacias leiteiras deste estado e a principal forragem utilizada no período seco do ano (abril a outubro) é a silagem de planta inteira de milho. Nessa região, quase $50 \%$ do milho cultivado é destinado à ensilagem. Normalmente, após a colheita do milho para a silagem, a maior parte das propriedades rurais da região mantém o solo descoberto até o início da nova safra, já que toda a parte aérea da planta de milho é colhida. A grande maioria dos produtores de milho para silagem da região geralmente não cultivam nenhuma cultura após a retirada da cultura de verão, deixando o solo descoberto a maior parte do ano.

Normalmente, o produtor colhe a silagem e deixa o solo nu até o início das chuvas (início de outubro). A permanência do solo em pousio contribui para maior infestação de plantas invasoras que, além de não produzirem volume adequado de palhada, favorecem o banco de sementes de plantas daninhas (Camargo \& Piza, 2007).

Geralmente no início da estação chuvosa, o solo é preparado com uma aração e duas gradagens. Embora alguns produtores já utilizem o SSD na região Central de Minas Gerais, a maioria trabalha no sistema de semeadura convencional (SSC) e sem rotação e/ou sucessão de culturas. O cultivo de milho sob milho no SSC ainda é mais danoso aos solos nas áreas de milho destinadas à silagem, devido à colheita de toda a planta e à falta de cobertura vegetal no outono-inverno.

Mesmo nas regiões de agricultura tradicional, como é o caso do estado do Paraná, predomina o uso de poucas espécies de cobertura. Em muitas regiões desse estado, cultiva-se principalmente aveia branca ou preta no inverno, enquanto culturas como tremoço, ervilhaca e nabo forrageiro são pouco difundidas (Borkert et al., 2003).

Se, por um lado, trabalhos que visam ao estudo de plantas para cobertura em áreas de produção de milho para silagem são escassos no Brasil, por outro, a possibilidade de sucesso das plantas de sucessão nessas áreas pode ser maior. Isso ocorre porque o ponto ideal de colheita do milho para silagem (30 a 33\% de massa seca) é no mínimo um mês anterior ao ponto de colheita do milho para grão seco. Dessa forma, parte do problema do déficit hídrico, que é o principal limitante dessas áreas cultivadas em sistema de sequeiro, poderia ser reduzido. Isso justifica, ainda mais, a necessidade de se estudar plantas de cobertura para áreas de cultivo de milho exclusivo para silagem.

São raros no Brasil estudos sobre plantas de cobertura em sucessão ao cultivo de milho para silagem, sendo que, para as condições do Cerrado mineiro, não foram encontrados trabalhos na literatura. A literatura consultada reporta trabalhos relacionados a espécies de cobertura em sucessão ao cultivo de milho para grão (Oliveira et al., 2002; Nunes et al., 2006; Camargo \& Piza, 2007; Carvalho et al., 2004; Torres et al., 2008; Torres \& Pereira, 2008). O objetivo deste trabalho foi avaliar o efeito de diferentes plantas de cobertura no acúmulo de macronutrientes na parte aérea das plantas 
de milho e nas diferentes frações da planta de milho (espigas, folhas, colmos) em área de produção de silagem na região Central de Minas Gerais, bem como o efeito das plantas de cobertura na produtividade de massa seca de plantas de milho.

\section{Material e Métodos}

Este estudo foi realizado numa área utilizada para cultivo de milho para silagem há mais de 15 anos sobre Latossolo Vermelho Amarelo, localizada no município de Matozinhos, MG, com coordenadas geográficas de $19^{\circ} 30^{\prime} \mathrm{S}$ e $44^{\circ} 1^{\prime}$ W. A caracterização química do solo, antes da implantação do experimento, é apresentada na Tabela 1.

$\mathrm{O}$ estudo foi iniciado no mês de março de 2010, quando foram semeadas as culturas de cobertura. $\mathrm{O}$ delineamento experimental utilizado foi o de blocos ao acaso, com quatro repetições. Os tratamentos foram constituídos de uma área de pousio e de oito espécies de cobertura - nabo forrageiro (Raphanus sativus), milheto (Pennisetum americanum (L.) Leek var. ADR 500), Brachiaria ruzziziensis e $B$. decumbens, crotalária júncea (Crotalarea juncea L.), tremoço (Lupinus albus L.), aveia preta (Avena strigosa) e girassol (Helianthus annuus). A dimensão de cada uma das parcelas foi de 7 x $20 \mathrm{~m}$, totalizando $140 \mathrm{~m}^{2}$.

A distribuição das sementes das plantas de cobertura foi realizada de forma manual, a lanço.
A fim de aumentar a qualidade da distribuição das sementes, misturou-se, na quantidade de cada semente de cada parcela, uma quantidade fixa de areia $\left(51\right.$ parcela $\left.^{-1}\right)$. As quantidades de sementes por hectare utilizadas em cada parcela foram: $20 \mathrm{~kg}$ de sementes para ambas as braquiárias; $25 \mathrm{~kg}$ para a parcela da crotalária; $15 \mathrm{~kg}$ para as parcelas com girassol, nabo ou milheto; e $70 \mathrm{~kg}$ para a parcela com semeadura de aveia.

Antes da semeadura das plantas de cobertura, a área foi subsolada a $25 \mathrm{~cm}$, com subsolador com rolo destorroador traseiro, com disco de corte na parte frontal e com presença de cinco hastes, espaçadas a $40 \mathrm{~cm}$. Imediatamente após a distribuição das plantas de cobertura, foi realizada uma incorporação com grade leve fechada.

Após 84 dias da semeadura das plantas de cobertura, avaliou-se a produtividade de massa seca das plantas de cobertura e realizou-se a roçada de todas as plantas de cobertura. Cada avaliação de produção de MS foi feita em três pontos por parcela, utilizando-se um quadrado de $0,5 \mathrm{~m}$ de dimensão. As plantas foram cortadas rente ao solo e imediatamente pesadas no campo. Das três amostras retiradas, duas foram devolvidas à parcela após a pesagem e uma foi levada ao laboratório; esta última foi seca em estufa a $60^{\circ} \mathrm{C}$, triturada e submetida à análise química para determinação dos teores totais de nutrientes $(\mathrm{C}, \mathrm{N}$, P, K, Mg, Ca, S), segundo Malavolta et al. (1997). As quantidades acumuladas de macronutrientes nas

TABELA 1. Atributos químicos do solo e teores de macronutrientes das camadas de 0 a 20 e 20 a $40 \mathrm{~cm}$.

\begin{tabular}{|c|c|c|c|c|c|c|c|c|c|c|c|c|c|}
\hline \multirow{2}{*}{$\begin{array}{c}\text { Prof. } \\
\mathrm{cm}\end{array}$} & \multirow{2}{*}{$\begin{array}{c}\mathrm{pH} \\
\mathrm{H}_{2} \mathrm{O}\end{array}$} & $\mathrm{P}$ & K & $\mathrm{S}$ & $\mathrm{Ca}$ & $\mathrm{Mg}$ & $\mathrm{Al}$ & $\mathrm{H}+\mathrm{Al}$ & SB & $\mathrm{t}$ & $\mathrm{T}$ & V & $\mathrm{MO}$ \\
\hline & & \multicolumn{3}{|c|}{------ $\mathrm{mg} \mathrm{dm}^{-3}$------- } & \multicolumn{7}{|c|}{ - - } & \multicolumn{2}{|c|}{------ \% ------ } \\
\hline $0-20$ & 5,6 & 50,3 & 122,0 & 5,0 & 4,3 & 1,2 & 0,5 & 5,2 & 5,8 & 6,3 & 11,0 & 52,7 & 3,0 \\
\hline $20-40$ & 5,4 & 35,2 & 66,0 & 9,8 & 4,0 & 0,9 & 0,2 & 5,2 & 5,1 & 5,3 & 10,3 & 49,3 & 2,4 \\
\hline
\end{tabular}


plantas de cobertura foram calculadas baseandose na concentração de nutrientes na parte aérea das plantas de cobertura $(\mathrm{g} / \mathrm{kg})$ e na massa seca $(\mathrm{kg})$ produzida na área amostrada $(0,5 \times 0,5 \mathrm{~m})$. Posteriormente, as quantidades acumuladas foram extrapoladas para um hectare $\left(10.000 \mathrm{~m}^{2}\right)$.

Em função do atraso das chuvas no mês de outubro de 2010 e da alta intensidade de chuvas no mês de novembro, a semeadura do milho foi realizada no dia 10 de dezembro de 2010 . Na semeadura, utilizou-se o híbrido P3862 H (híbrido $\mathrm{Bt})$, no espaçamento de $0,7 \mathrm{~m}$ entrelinhas, com 4,3 sementes por metro linear (61.400 sementes por hectare). As sementes utilizadas foram tratadas industrialmente com inseticidas de princípio ativo (PA) fripronil e tiametoxan. Além disso, foi realizado o tratamento com o inseticida no sulco de semeadura de PA clorpirifos, na dosagem de 0,961 ha-1.

A adubação de base foi realizada com $400 \mathrm{~kg}$ $\mathrm{ha}^{-1}$ de NPK 08.20.16 (32 $\mathrm{kg} \mathrm{ha}^{-1}$ de N, $80 \mathrm{~kg} \mathrm{ha}^{-1}$ de $\mathrm{P}_{2} \mathrm{O}_{5}$ e $64 \mathrm{~kg} \mathrm{ha}^{-1}$ de $\mathrm{K}_{2} \mathrm{O}$ ). A adubação de cobertura foi realizada no estágio V4 da cultura, com $400 \mathrm{~kg}$ ha $^{-1}$ de NPK 25.00 .25 (112,5 $\mathrm{kg} \mathrm{ha}^{-1}$ de $\mathrm{N}$ e 112,5 $\mathrm{kg} \mathrm{ha}^{-1}$ de $\mathrm{K}_{2} \mathrm{O}$ ). $\mathrm{O}$ adubo foi aplicado de forma enterrada a $5 \mathrm{~cm}$ de profundidade, com o cultivador de disco central no meio das linhas de semeadura. Antes da adubação de cobertura da cultura do milho, foi realizado o manejo químico de ervas daninhas com herbicidas atrazina (125 gramas de $\mathrm{PA} \mathrm{ha}^{-1}$ ) e tebotriona (76 gramas de PA ha-1).

A colheita do milho foi realizada no dia 25 de março de 2011. Para determinação da produtividade de massa natural e de massa seca, foram colhidas as plantas de três fileiras centrais de cada parcela, com $3 \mathrm{~m}$ de comprimento $\left(6,3 \mathrm{~m}^{2}\right)$, as quais foram pesadas imediatamente após a colheita. Após pesagem dos materiais a campo, foram separadas cinco plantas por parcela, separando as diferentes partes da planta (caule, folha e espiga) para pesagem no campo e posterior determinação de massa seca (após secagem) e dos teores de nutrientes.Após a pesagem dos materiais a campo, as diferentes partes das plantas foram secas em estufa a $60{ }^{\circ} \mathrm{C}$ até as amostras alcançarem peso constante e, em seguida, foram moídas em moinho de facas tipo Willye, apresentando granulometria média inferior a $2 \mathrm{~mm}$. Posteriormente, foram determinados os teores dos macronutrientes ( $\mathrm{N}, \mathrm{P}, \mathrm{K}, \mathrm{Mg}, \mathrm{Ca}$ e $\mathrm{S}$ ) nas diferentes partes da planta (caule, folhas e espigas), conforme Malavolta et al. (1997). As quantidades acumuladas de macronutrientes nas diferentes partes das plantas de milho (folha, colmo e espiga) foram calculadas baseando-se na concentração de nutrientes em cada uma das partes da planta obtidas nas cinco plantas selecionadas e pela quantidade de massa seca produzida na parcela $\left(6,3 \mathrm{~m}^{2}\right)$. Posteriormente, as quantidades acumuladas foram extrapoladas para um hectare $\left(10.000 \mathrm{~m}^{2}\right)$.

Todos os dados obtidos foram submetidos a análises de variância e a testes de média, conforme o delineamento descrito no item "Material e Métodos". As médias foram comparadas pelo teste de Tukey $(\mathrm{P}<0,05)$.

\section{Resultados e Discussão}

As culturas de girassol, milheto, nabo forrageiro e crotalária apresentaram alta produtividade de MS (Tabela 2). O nabo forrageiro apresentou produtividade superior àquelas descritas por Derpsch \& Calegari (1992) e Calegari (1998) para o estado do Paraná, que foi de $3.000 \mathrm{~kg} \mathrm{ha}^{-1}$ de MS da parte aérea (valores descritos oscilando entre 2.000 e $6.000 \mathrm{~kg}$ ha ${ }^{-1}$ de MS no estádio de floração). 
TABELA 2. Produtividade de massa seca (MS) da parte aérea das plantas de cobertura.

\begin{tabular}{cc}
\hline Tratamentos & Massa seca $\left(\mathrm{kg} \mathrm{ha}^{-1}\right)$ \\
\hline Girassol & $10258 \mathrm{~A}$ \\
Milheto ADR 500 & $8603 \mathrm{AB}$ \\
Nabo forrageiro & $6749 \mathrm{BC}$ \\
Crotalária juncea & $5777 \mathrm{BCD}$ \\
Braquiária decumbens & $4727 \mathrm{CDE}$ \\
Braquiária ruziziensis & $3694 \mathrm{DE}$ \\
Tremoço & $3692 \mathrm{DE}$ \\
Aveia & $2802 \mathrm{DE}$ \\
Pousio & $2621 \mathrm{E}$ \\
\hline
\end{tabular}

${ }^{\top}$ Médias seguidas de mesma letra, maiúscula na coluna, não diferem entre si $(\mathrm{p}<0,05)$ pelo teste de Tukey.

Entre as culturas com maior produtividades de MS, apenas a crotalária produziu menos do que 6 t ha ${ }^{-1}$ de MS, que é descrita como a mínima quantidade de palha necessária para a manutenção do SSD (Alvarenga et al., 2001).

As quantidades de macronutrientes acumuladas na parte aérea das plantas de cobertura são apresentadas na Tabela 3. De forma geral, as quantidades acumuladas de macronutrientes foram elevadas, comparadas às observadas por alguns autores (Oliveira et al., 2002; Crusciol et al., 2005; Teixeira et al., 2005; Torres et al., 2005), o que pode ser atribuído, em parte, às elevadas quantidades de MS observadas nesse estudo.

No presente estudo, com exceção das quantidades de $\mathrm{N}$ acumuladas, de modo geral, as quantidades de $\mathrm{P}, \mathrm{K}, \mathrm{Ca}, \mathrm{Mg}$ e $\mathrm{S}$ foram maiores nas plantas que apresentaram as maiores quantidades acumuladas de

TABELA 3. Acúmulo de macronutrientes na parte aérea das plantas de cobertura.

\begin{tabular}{|c|c|c|c|c|c|c|c|}
\hline \multirow{2}{*}{ Tratamento } & $\mathrm{N}$ & $\mathrm{C}$ & $\mathrm{K}$ & $\mathrm{P}$ & $\mathrm{Mg}$ & $\mathrm{Ca}$ & $\mathrm{S}$ \\
\hline & & & & $\mathrm{kg} \mathrm{ha}^{-1}$ & & & \\
\hline Girassol & $123,5 \mathrm{AB}$ & $4880,5 \mathrm{~A}$ & $184,1 \mathrm{~A}$ & $26,4 \mathrm{AB}$ & $30,6 \mathrm{~A}$ & $189,5 \mathrm{AB}$ & $21,9 \mathrm{~B}$ \\
\hline Milheto ADR 500 & $159,3 \mathrm{ABC}$ & $4087,8 \mathrm{AB}$ & $153,5 \mathrm{AB}$ & $20,1 \mathrm{ABC}$ & $25,1 \mathrm{ABC}$ & $53,2 \mathrm{C}$ & $16,5 \mathrm{BC}$ \\
\hline Nabo forrageiro & $181,7 \mathrm{AB}$ & $3146,8 \mathrm{BC}$ & $125,7 \mathrm{ABC}$ & $27,4 \mathrm{~A}$ & $28,3 \mathrm{AB}$ & $231,3 \mathrm{~A}$ & $39,8 \mathrm{~A}$ \\
\hline Crotalária juncea & $196,4 \mathrm{~A}$ & $2773,5 \mathrm{BCD}$ & $73,7 \mathrm{CD}$ & $19,5 \mathrm{ABC}$ & $20,3 \mathrm{ABCD}$ & 91,9 BC & $7,8 \mathrm{BC}$ \\
\hline Braquiária decumbens & $123,4 \mathrm{ABC}$ & 2181,7 CDE & $95,4 \mathrm{BCD}$ & $12,2 \mathrm{BC}$ & $9,4 \mathrm{CD}$ & $25,8 \mathrm{C}$ & $10,4 \mathrm{BC}$ \\
\hline Braquiária ruziziensis & $107,1 \mathrm{ABC}$ & $1712,6 \mathrm{CDE}$ & $71,4 \mathrm{CD}$ & $10,7 \mathrm{BC}$ & $12,4 \mathrm{BCD}$ & $32,4 \mathrm{C}$ & $10,5 \mathrm{BC}$ \\
\hline Tremoço & $107,0 \mathrm{ABC}$ & $1719 \mathrm{CDE}$ & $59,0 \mathrm{D}$ & $11 \mathrm{BC}$ & $10,0 \mathrm{CD}$ & $45,0 \mathrm{C}$ & $9,6 \mathrm{BC}$ \\
\hline Aveia & $67,1 \mathrm{C}$ & $1376,2 \mathrm{DE}$ & $53,4 \mathrm{D}$ & $9,2 \mathrm{C}$ & 7,9 D & $17,0 \mathrm{C}$ & $6,4 \mathrm{C}$ \\
\hline Pousio & $84,6 \mathrm{BC}$ & $1205 \mathrm{E}$ & $48,7 \mathrm{D}$ & $8,1 \mathrm{C}$ & $8,2 \mathrm{D}$ & $24,1 \mathrm{C}$ & $7,2 \mathrm{C}$ \\
\hline
\end{tabular}

${ }^{1}$ Médias seguidas de mesma letra, maiúscula na coluna, não diferem entre si $(\mathrm{p}<0,05)$ pelo teste de Tukey. 
MS (Tabela 2) - girassol, milheto e nabo. Em trabalho desenvolvido por Carvalho et al. (2008) em Planaltina, DF, o nabo forrageiro apresentou as maiores quantidades acumuladas $\left(\mathrm{kg} \mathrm{ha}^{-1}\right)$ de $\mathrm{P}$, comparado a outras de plantas de cobertura, semelhante ao observado neste trabalho. Uma das maiores quantidades de $\mathrm{N}$ foi acumulada pela crotalária, possivelmente devido à fixação simbiótica do $\mathrm{N}$ atmosférico, enquanto uma das menores quantidades foi acumulada pela aveia (Tabela 3), possivelmente devido à sua baixa produtividade de MS (Tabela 2). No entanto, a aveia apresenta elevado potencial de absorção e acumulação de $\mathrm{N}$, alcançando quase $150 \mathrm{~kg} \mathrm{ha}^{-1}$ (Heinzmann, 1985) quando é cultivada em condições favoráveis ao seu desenvolvimento.

A produtividade de MS da parte aérea das plantas de milho e das diferentes frações da planta (folha, colmo e espiga) não variou com as plantas de cobertura (Tabela 4), diferentemente do que vem sendo observado em outras regiões do país
(Gonçalves \& Ceretta, 1999; Carvalho et al., 2004; Torres et al., 2005).

No estudo de Carvalho et al. (2004) em solos sob Cerrado de Selvíria, MS, as maiores produtividades foram obtidas quando o milho foi cultivado após a crotalária. Em outro trabalho desenvolvido em Santa Maria, RS, as plantas de milho cultivadas em sucessão à ervilhaca e ao nabo forrageiro apresentaram as maiores produtividades de MS e as maiores quantidades acumuladas de $\mathrm{N}$, comparadas às plantas cultivadas após gramíneas. Também em Santa Maria, RS, o rendimento do milho cultivado após a aveia foi inferior ao do milho cultivado em sucessão a leguminosas (Gonçalves \& Ceretta, 1999). Carvalho et al. (2004) acreditam que a maior produtividade do milho após a crotalária foi devido à maior quantidade de $\mathrm{N}$ residual deixada no solo pela crotalária. Em Uberaba, MG, dentre sete culturas de coberturas estudadas por Torres et al. (2005), a crotalária juncea foi a que apresentou o maior acúmulo e liberação de N.

TABELA 4. Produtividade de massa seca (MS) das diferentes frações da planta de milho (folha: MS-Folha, colmo: MS-Colmo e espiga: MS-Espiga) e produtividade de MS da parte aérea total das plantas de milho, em função das plantas de cobertura.

\begin{tabular}{|c|c|c|c|c|}
\hline \multirow{2}{*}{ Tratamento } & MS Folha & MS Colmo & MS Espiga & Total MS \\
\hline & \multicolumn{4}{|c|}{----------------------------- kg ha' } \\
\hline Aveia & 2538,2 & 5185,6 & 2804,8 & 10528,6 \\
\hline Braquiária decumbens & 2724,2 & 5417,2 & 2876,1 & 11017,5 \\
\hline Braquiária ruziziensis & 2264,6 & 4402,3 & 1728,4 & 8395,2 \\
\hline Crotalária juncea & 2314,8 & 4850,7 & 1545,7 & 8711,1 \\
\hline Girassol & 2671,8 & 5501,9 & 2370,4 & 10544,0 \\
\hline Nabo forrageiro & 3046,3 & 6431,6 & 3694,3 & 13172,2 \\
\hline Milheto ADR 500 & 2243,9 & 4569,1 & 1978,2 & 8791,3 \\
\hline Tremoço & 3368,1 & 7244,9 & 2132,6 & 12745,6 \\
\hline Pousio & 2639,7 & 5572,0 & 2666,9 & 10878,6 \\
\hline
\end{tabular}


No atual trabalho, a resposta do milho às culturas antecessoras pode ter sofrido influência das condições climáticas durante seu cultivo. Houve acentuado veranico entre os meses de janeiro e fevereiro de 2011. Entre os dias 17 de janeiro e 23 de fevereiro de 2011, ocorreram apenas $6 \mathrm{~mm}$ de chuvas, quando o milho se encontrava com menos de 40 dias de desenvolvimento após a semeadura. Na Figura 1, é apresentada a precipitação mensal ocorrida na área de estudo, referente ao período de $1^{\circ}$ de janeiro de 2010 a 31 de maio de 2011. Possivelmente, em condições climáticas mais favoráveis, a resposta do milho às culturas sucessoras poderia ser diferente.

Com exceção das concentrações de $\mathrm{N}$ e $\mathrm{S}$, as concentrações de $\mathrm{P}, \mathrm{K}, \mathrm{Ca}$ e $\mathrm{Mg}$ nas folhas de milho não variaram com as plantas de cobertura (Tabela 5). No caso do N, a maior concentração foi observada no milho cultivado após o girassol e a menor no milho em sucessão ao tremoço. Embora seja esperada maior concentração de $\mathrm{N}$ em plantas de milho cultivadas após as leguminosas, observou-se que o girassol apresentou produtividade de MS superior à encontrada nas leguminosas (Tabela 2), o que pode ter influenciado a disponibilidade de $\mathrm{N}$ no solo.

No caso do $\mathrm{S}$, a maior e a menor concentrações foliares ocorreram nas plantas de milho cultivadas após nabo forrageiro e $B$. ruziziensis, respectivamente. Esse fato se justifica pela grande exigência do nabo forrageiro em enxofre, o qual apresenta alta capacidade de absorção e acúmulo desse nutriente (Rheinheimer et al., 2005). Dessa forma, acredita-se que o nabo forrageiro seja uma planta importante na reciclagem do enxofre das camadas mais profundas para a superfície do solo, beneficiando assim plantas cultivadas em sucessão.

Como os teores de macronutrientes relacionados na Tabela 5 são da planta em final de ciclo (época da colheita da silagem), além de serem de todas as folhas das plantas (folhas novas, maduras e velhas), não foi possível compará-los diretamente com os teores considerados adequados para o milho, já que para isso deveria ter sido coletada apenas a

TABELA 5. Concentração de macronutrientes nas folhas das plantas de milho, em função das plantas de cobertura.

\begin{tabular}{|c|c|c|c|c|c|c|}
\hline Tratamento & $\mathrm{N}$ & $\mathrm{P}$ & $\mathrm{K}$ & $\mathrm{Ca}$ & $\mathrm{Mg}$ & $\mathrm{S}$ \\
\hline Aveia & $21,1 \mathrm{AB}$ & $2,1 \mathrm{~A}$ & $11,3 \mathrm{~A}$ & $7,6 \mathrm{~A}$ & $1,6 \mathrm{~A}$ & $1,75 \mathrm{AB}$ \\
\hline Braquiária decumbens & $21,3 \mathrm{AB}$ & $2,1 \mathrm{~A}$ & $11,9 \mathrm{~A}$ & $7,4 \mathrm{~A}$ & $1,7 \mathrm{~A}$ & $1,77 \mathrm{AB}$ \\
\hline Braquiária ruziziensis & $20,9 \mathrm{AB}$ & $2,1 \mathrm{~A}$ & $11,2 \mathrm{~A}$ & $6,7 \mathrm{~A}$ & $1,5 \mathrm{~A}$ & $1,67 \mathrm{~B}$ \\
\hline Crotalária juncea & $21,6 \mathrm{AB}$ & $2,2 \mathrm{~A}$ & $10,5 \mathrm{~A}$ & $7,6 \mathrm{~A}$ & $1,8 \mathrm{~A}$ & $1,72 \mathrm{AB}$ \\
\hline Girassol & $23,6 \mathrm{~A}$ & $2,2 \mathrm{~A}$ & $10,3 \mathrm{~A}$ & $8,4 \mathrm{~A}$ & $1,6 \mathrm{~A}$ & $1,90 \mathrm{AB}$ \\
\hline Nabo forrageiro & $22,6 \mathrm{AB}$ & $2,2 \mathrm{~A}$ & $11,8 \mathrm{~A}$ & $8,3 \mathrm{~A}$ & $1,8 \mathrm{~A}$ & $2,00 \mathrm{~A}$ \\
\hline Milheto ADR 500 & $21,3 \mathrm{AB}$ & $2,3 \mathrm{~A}$ & $10,5 \mathrm{~A}$ & $7,7 \mathrm{~A}$ & $1,7 \mathrm{~A}$ & $1,82 \mathrm{AB}$ \\
\hline Tremoço & $19,6 \mathrm{~B}$ & $2,4 \mathrm{~A}$ & $9,5 \mathrm{~A}$ & $7,8 \mathrm{~A}$ & $1,8 \mathrm{~A}$ & $1,80 \mathrm{AB}$ \\
\hline Pousio & $20,0 \mathrm{~B}$ & $2,1 \mathrm{~A}$ & $10,8 \mathrm{~A}$ & $7,0 \mathrm{~A}$ & $1,8 \mathrm{~A}$ & $1,80 \mathrm{AB}$ \\
\hline
\end{tabular}

${ }^{1}$ Médias seguidas de mesma letra, maiúscula na coluna, não diferem entre si $(\mathrm{p}<0,05)$ pelo teste de Tukey. 


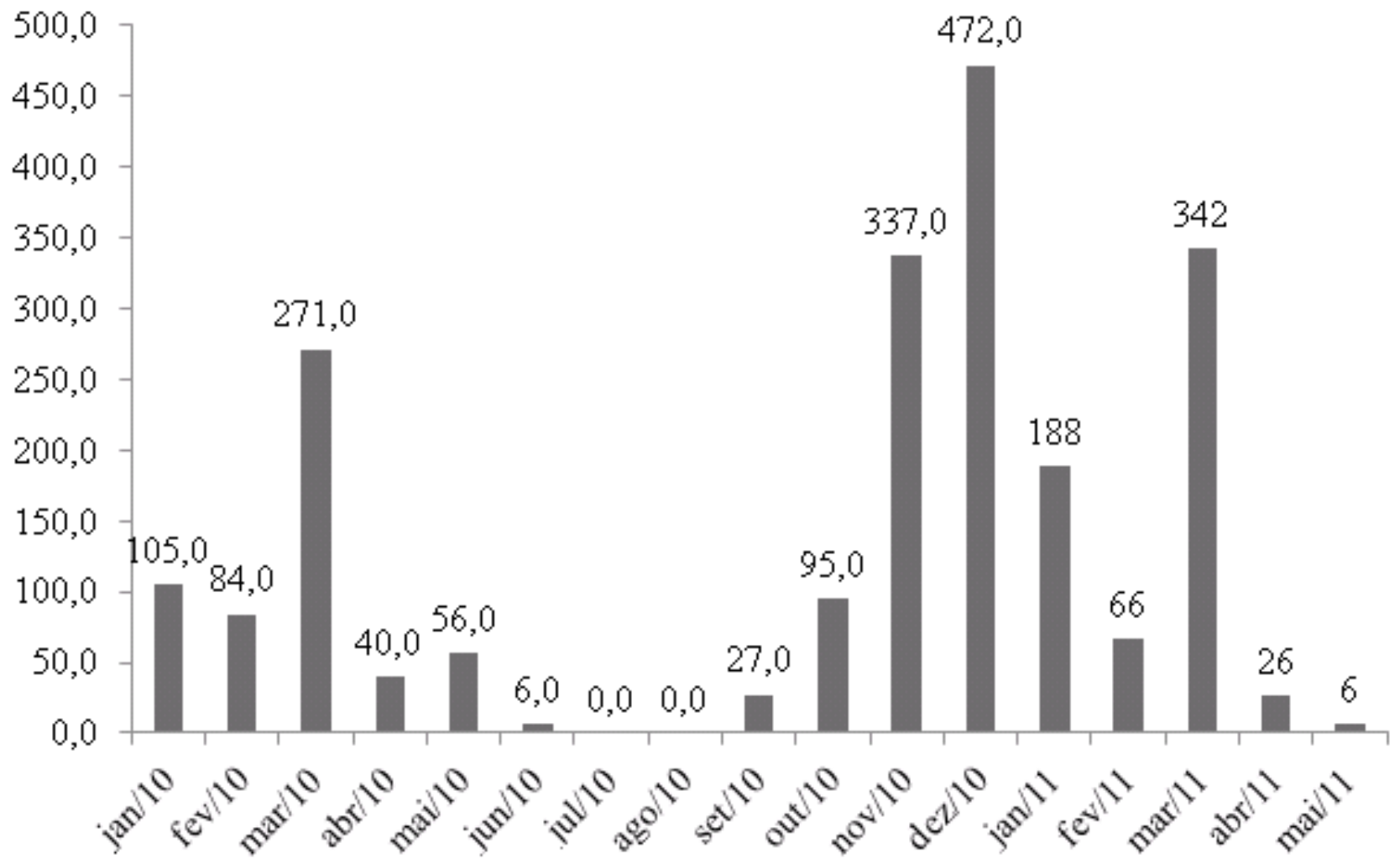

FIGURA 1. Precipitação pluvial acumulada por mês no período de $1^{\circ}$ de janeiro de 2010 a 31 de maio de 2011.

folha considerada diagnóstica para a análise foliar, que, de acordo com Malavolta et al. (1997), é a folha oposta e abaixo da espiga, coletada na época do início do florescimento. No entanto, é possível fazer algumas inferências. Com exceção das concentrações foliares de $\mathrm{N}$ e $\mathrm{K}$ nas folhas, os teores de $\mathrm{P}, \mathrm{Ca}, \mathrm{Mg}$ e $\mathrm{S}$ estavam dentro ou acima daqueles considerados adequados para o milho, conforme Coelho \& França (1995). Segundo esses autores, os teores adequados para a cultura do milho variam de 27,5-32,5; 1,9-3,5; 17,5-29,7; 2,3-4; 1,5-4 e 1,5 - 2,1 $\mathrm{g} \mathrm{ha}^{-1}$, respectivamente para $\mathrm{N}, \mathrm{P}, \mathrm{K}, \mathrm{Ca}, \mathrm{Mg}$ e $\mathrm{S}$.

As quantidades acumuladas de macronutrientes nas folhas da planta de milho apresentaram variação apenas para o P e o Ca (Tabela 6), embora tenham havido diferenças nas concentrações foliares de $\mathrm{N}$ e S nas plantas de milho (Tabela 5).

As plantas de milho cultivadas sob o tremoço foram aquelas que acumularam as maiores quantidades de $\mathrm{P}$ e $\mathrm{Ca}$ nas folhas, provavelmente devido às maiores produtividades de MS do milho cultivado sob tremoço, que, embora não tendo sido significativamente diferente, contribuiu para aumentar a quantidade de $\mathrm{P}$ e Ca nas folhas de milho. Por outro lado, as plantas de milho cultivadas em sucessão à B. decumbens e milheto foram aquelas que apresentaram as menores quantidades acumuladas de $\mathrm{Ca}$ e as plantas cultivadas sob B. ruziziensis as menores quantidades de P. Como não houve diferença nas concentrações foliares desses nutrientes nas folhas de milho, 
TABELA 6. Quantidades de macronutrientes acumuladas nas folhas das plantas de milho, em função das plantas de cobertura.

\begin{tabular}{|c|c|c|c|c|c|c|}
\hline \multirow{2}{*}{ Tratamento } & $\mathrm{N}$ & $\mathrm{P}$ & K & $\mathrm{Ca}$ & $\mathrm{Mg}$ & $\mathrm{S}$ \\
\hline & \multicolumn{6}{|c|}{-------------------------------- kg ha' } \\
\hline Aveia & $53,9 \mathrm{~A}$ & $5,2 \mathrm{AB}$ & $29,3 \mathrm{~A}$ & $19,6 \mathrm{AB}$ & $4,2 \mathrm{~A}$ & $4,5 \mathrm{~A}$ \\
\hline Braquiária decumbens & $58,9 \mathrm{~A}$ & $5,5 \mathrm{AB}$ & $33,2 \mathrm{~A}$ & $19,8 \mathrm{AB}$ & $4,6 \mathrm{~A}$ & $4,8 \mathrm{~A}$ \\
\hline Braquiária ruziziensis & $47,9 \mathrm{~A}$ & $4,8 \mathrm{~B}$ & $25,9 \mathrm{~A}$ & $15,2 \mathrm{~B}$ & $3,4 \mathrm{~A}$ & $3,8 \mathrm{~A}$ \\
\hline Crotalária juncea & $51,0 \mathrm{~A}$ & $5,2 \mathrm{AB}$ & $24,8 \mathrm{~A}$ & $17,6 \mathrm{AB}$ & $4,4 \mathrm{~A}$ & $4,0 \mathrm{~A}$ \\
\hline Girassol & $64,4 \mathrm{~A}$ & $5,8 \mathrm{AB}$ & $28,5 \mathrm{~A}$ & $21,5 \mathrm{AB}$ & $4,4 \mathrm{~A}$ & $5,1 \mathrm{~A}$ \\
\hline Nabo forrageiro & $68,5 \mathrm{~A}$ & $6,6 \mathrm{~A}$ & $36,2 \mathrm{~A}$ & $25,2 \mathrm{AB}$ & $5,5 \mathrm{~A}$ & $6,1 \mathrm{~A}$ \\
\hline Milheto ADR 500 & $48,2 \mathrm{~A}$ & $5,2 \mathrm{AB}$ & $24,1 \mathrm{~A}$ & $17,8 \mathrm{~B}$ & $3,8 \mathrm{~A}$ & $4,2 \mathrm{~A}$ \\
\hline Tremoço & $68,2 \mathrm{~A}$ & $7,9 \mathrm{~A}$ & $32,0 \mathrm{~A}$ & $26,0 \mathrm{~A}$ & $5,8 \mathrm{~A}$ & $6,1 \mathrm{~A}$ \\
\hline Pousio & $52,8 \mathrm{~A}$ & $5,5 \mathrm{AB}$ & $28,6 \mathrm{~A}$ & $18,8 \mathrm{AB}$ & $4,9 \mathrm{~A}$ & $4,8 \mathrm{~A}$ \\
\hline
\end{tabular}

${ }^{1}$ Médias seguidas de mesma letra, maiúscula na coluna, não diferem entre si $(\mathrm{p}<0,05)$ pelo teste de Tukey.

as variações nas quantidades acumuladas devem estar relacionadas à produção de MS das folhas do milho.

As concentrações de macronutrientes nos colmos da planta de milho não variaram com os tratamentos, com exceção do K (Tabela 7). Em plantas cultivadas para silagem, o potássio é exportado em grande quantidade do solo, em função da colheita de toda a parte aérea da planta. Segundo Coelho \& França (1995), cerca de 70\% do nutriente se concentra nas folhas e no colmo, sendo que as folhas são colhidas em plantas de milho para silagem. Assim, plantas de cobertura com capacidade de reciclar o

TABELA 7. Concentração de macronutrientes nos colmos das plantas de milho, em função das plantas de cobertura.

\begin{tabular}{lcccccc}
\hline \multicolumn{1}{c}{ Tratamento } & $\mathrm{N}$ & $\mathrm{P}$ & $\mathrm{K}$ & $\mathrm{Ca}$ & $\mathrm{Mg}$ & $\mathrm{S}$ \\
\hline Aveia & 7,5 A & $0,8 \mathrm{~A}$ & $6,8 \mathrm{AB}$ & $3,4 \mathrm{~A}$ & $1,4 \mathrm{~A}$ & $0,8 \mathrm{~A}$ \\
Braquiária decumbens & $7,6 \mathrm{~A}$ & $0,9 \mathrm{~A}$ & $8,1 \mathrm{~A}$ & $3,2 \mathrm{~A}$ & $1,4 \mathrm{~A}$ & $0,7 \mathrm{~A}$ \\
Braquiária ruziziensis & $7,8 \mathrm{~A}$ & $1,0 \mathrm{~A}$ & $7,7 \mathrm{AB}$ & $3,2 \mathrm{~A}$ & $1,4 \mathrm{~A}$ & $0,7 \mathrm{~A}$ \\
Crotalária juncea & 8,6 A & $1,0 \mathrm{~A}$ & $6,0 \mathrm{AB}$ & $3,5 \mathrm{~A}$ & $1,5 \mathrm{~A}$ & $0,7 \mathrm{~A}$ \\
Girassol & 6,9 A & $0,9 \mathrm{~A}$ & $5,3 \mathrm{~B}$ & $3,5 \mathrm{~A}$ & $1,3 \mathrm{~A}$ & $0,7 \mathrm{~A}$ \\
Nabo forrageiro & $7,7 \mathrm{~A}$ & $1,0 \mathrm{~A}$ & $7,7 \mathrm{AB}$ & $3,5 \mathrm{~A}$ & $1,5 \mathrm{~A}$ & $0,7 \mathrm{~A}$ \\
Milheto ADR 500 & $7,8 \mathrm{~A}$ & $1,0 \mathrm{~A}$ & $6,5 \mathrm{AB}$ & $3,5 \mathrm{~A}$ & $1,4 \mathrm{~A}$ & $0,7 \mathrm{~A}$ \\
Tremoço & $8,4 \mathrm{~A}$ & $1,1 \mathrm{~A}$ & $6,1 \mathrm{AB}$ & $3,7 \mathrm{~A}$ & $1,4 \mathrm{~A}$ & $0,7 \mathrm{~A}$ \\
Pousio & 8,4 A & $0,9 \mathrm{~A}$ & $6,0 \mathrm{AB}$ & $3,5 \mathrm{~A}$ & $1,5 \mathrm{~A}$ & $0,7 \mathrm{~A}$ \\
\hline
\end{tabular}

${ }^{1}$ Médias seguidas de mesma letra, maiúscula na coluna, não diferem entre si $(\mathrm{p}<0,05)$ pelo teste de Tukey. 
potássio podem trazer benefícios à cultura do milho cultivada em sucessão. Torres \& Pereira (2008) observaram grande acúmulo de potássio pelas plantas de Brachiaria brizantha e milheto, comparadas a outras cinco culturas de cobertura, como o sorgo forrageiro (Raphanus sativus), o guandu (Cajanus cajan), a crotalária e a aveia preta. Enquanto as culturas do milheto e da braquiária acumularam 219 e $215 \mathrm{~kg} \mathrm{ha}^{-1}$ de $\mathrm{K}$, as culturas do sorgo, da crotalária, da aveia e do guandu acumularam apenas $105,59,33$ e $31 \mathrm{~kg} \mathrm{ha}^{-1}$, após 110 dias de crescimento.

No presente estudo, as plantas de milho cultivadas após a $B$. decumbens mostraram concentração de $\mathrm{K}$ nos colmos superior àquelas cultivadas após o girassol (Tabela 7). Por outro lado, as quantidades de $\mathrm{k}$ acumuladas nos colmos das plantas de milho cultivadas após o girassol e $B$. decumbens foram semelhantes (Tabela 8).

As quantidades acumuladas de macronutrientes nos colmos das plantas de milho apresentaram variação apenas para o P e o Ca (Tabela 8). Como não houve diferença nos teores desses nutrientes no colmo das plantas de milho (Tabela 7), as variações no acúmulo são devidas às variações na produção de MS pelas plantas de milho (Tabela 4).

Somente as concentrações de $\mathrm{N}$ e $\mathrm{S}$ nas espigas das plantas de milho variaram com os tratamentos (Tabela 9). As plantas de milho cultivadas após a crotalária apresentaram maior concentração de $\mathrm{N}$ nas espigas do que as plantas cultivadas sob a aveia. Mesmo que essa maior concentração de $\mathrm{N}$ não tenha influenciado de forma significativa a produção de MS do milho (Tabela 4), o dado é importante por mostrar que, em condições climáticas mais adequadas, há potencial de maior fornecimento de $\mathrm{N}$ às plantas de milho quando as mesmas são cultivadas após a crotalária. Na literatura, é conhecido o efeito das plantas da família Fabaceae, particularmente na capacidade de formarem associações simbióticas com bactérias fixadoras de $\mathrm{N}_{2}$. Como resultado da simbiose, aumenta a quantidade de $\mathrm{N}$ disponível às culturas após o manejo da leguminosa (Perin et al.,

TABELA 8. Quantidades de macronutrientes acumuladas nos colmos das plantas de milho, em função das plantas de cobertura.

\begin{tabular}{|c|c|c|c|c|c|c|}
\hline \multirow{2}{*}{ Tratamento } & $\mathrm{N}$ & $\mathrm{P}$ & $\mathrm{K}$ & $\mathrm{Ca}$ & $\mathrm{Mg}$ & $\mathrm{S}$ \\
\hline & \multicolumn{6}{|c|}{-----------------------------------------} \\
\hline Aveia & $37,4 \mathrm{~A}$ & $4,1 \mathrm{~B}$ & $34,1 \mathrm{~A}$ & $17,6 \mathrm{AB}$ & $7,1 \mathrm{~A}$ & $3,8 \mathrm{~A}$ \\
\hline Braquiária decumbens & $41,9 \mathrm{~A}$ & $4,7 \mathrm{AB}$ & $45,7 \mathrm{~A}$ & $17,1 \mathrm{AB}$ & $7,5 \mathrm{~A}$ & $3,6 \mathrm{~A}$ \\
\hline Braquiária ruziziensis & $35,0 \mathrm{~A}$ & $4,1 \mathrm{~B}$ & $33,3 \mathrm{~A}$ & $13,8 \mathrm{~B}$ & $6,0 \mathrm{~A}$ & $2,9 \mathrm{~A}$ \\
\hline Crotalária juncea & $42,5 \mathrm{~A}$ & $5,2 \mathrm{AB}$ & $28,8 \mathrm{~A}$ & $16,7 \mathrm{AB}$ & $7,5 \mathrm{~A}$ & $3,4 \mathrm{~A}$ \\
\hline Girassol & $38,7 \mathrm{~A}$ & $5,1 \mathrm{AB}$ & $30,6 \mathrm{~A}$ & $18,4 \mathrm{AB}$ & $7,2 \mathrm{~A}$ & $4,1 \mathrm{~A}$ \\
\hline Nabo forrageiro & $49,7 \mathrm{~A}$ & $6,1 \mathrm{AB}$ & $50,3 \mathrm{~A}$ & $22,4 \mathrm{AB}$ & $9,5 \mathrm{~A}$ & $4,7 \mathrm{~A}$ \\
\hline Milheto ADR 500 & $36,2 \mathrm{~A}$ & $4,3 \mathrm{AB}$ & $29,6 \mathrm{~A}$ & $15,9 \mathrm{~B}$ & $6,0 \mathrm{~A}$ & $3,2 \mathrm{~A}$ \\
\hline Tremoço & $60,1 \mathrm{~A}$ & $7,6 \mathrm{~A}$ & $44,5 \mathrm{~A}$ & $26,4 \mathrm{~A}$ & $9,9 \mathrm{~A}$ & $5,2 \mathrm{~A}$ \\
\hline Pousio & $46,3 \mathrm{~A}$ & $5,0 \mathrm{~B}$ & $32,7 \mathrm{~A}$ & $19,2 \mathrm{AB}$ & $8,3 \mathrm{~A}$ & $3,9 \mathrm{~A}$ \\
\hline
\end{tabular}

${ }^{1}$ Médias seguidas de mesma letra, maiúscula na coluna, não diferem entre si $(\mathrm{p}<0,05)$ pelo teste de Tukey. 
TABELA 9. Concentração de macronutrientes nas espigas das plantas de milho, em função das plantas de cobertura.

\begin{tabular}{|c|c|c|c|c|c|c|}
\hline Tratamento & $\mathrm{N}$ & $\mathrm{P}$ & $\mathrm{K}$ & $\mathrm{Ca}$ & $\mathrm{Mg}$ & $\mathrm{S}$ \\
\hline & & & & & & \\
\hline Aveia & $9,7 \mathrm{~B}$ & $2,7 \mathrm{~A}$ & $9,9 \mathrm{~A}$ & $1,4 \mathrm{~A}$ & $1,5 \mathrm{~A}$ & $1,2 \mathrm{~A}$ \\
\hline Braquiária decumbens & $12,7 \mathrm{AB}$ & $3,0 \mathrm{~A}$ & $10,8 \mathrm{~A}$ & $1,3 \mathrm{~A}$ & $1,6 \mathrm{~A}$ & $1,2 \mathrm{~A}$ \\
\hline Braquiária ruziziensis & $12,4 \mathrm{AB}$ & $2,7 \mathrm{~A}$ & $10,6 \mathrm{~A}$ & $1,2 \mathrm{~A}$ & $1,4 \mathrm{~A}$ & $1,2 \mathrm{~A}$ \\
\hline Crotalária juncea & $13,1 \mathrm{~A}$ & $2,6 \mathrm{~A}$ & $10,2 \mathrm{~A}$ & $1,4 \mathrm{~A}$ & $1,4 \mathrm{~A}$ & $1,2 \mathrm{~A}$ \\
\hline Girassol & $11,5 \mathrm{AB}$ & $2,3 \mathrm{~A}$ & $8,9 \mathrm{~A}$ & $1,4 \mathrm{~A}$ & $1,4 \mathrm{~A}$ & $1,0 \mathrm{~B}$ \\
\hline Nabo forrageiro & $11,3 \mathrm{AB}$ & $2,9 \mathrm{~A}$ & $9,4 \mathrm{~A}$ & $1,3 \mathrm{~A}$ & $1,7 \mathrm{~A}$ & $1,2 \mathrm{~A}$ \\
\hline Milheto ADR 500 & $11,6 \mathrm{AB}$ & $2,4 \mathrm{~A}$ & $9,5 \mathrm{~A}$ & $1,3 \mathrm{~A}$ & $1,5 \mathrm{~A}$ & $1,1 \mathrm{~B}$ \\
\hline Tremoço & $11,3 \mathrm{AB}$ & $2,1 \mathrm{~A}$ & $9,2 \mathrm{~A}$ & $1,4 \mathrm{~A}$ & $1,4 \mathrm{~A}$ & $1,0 \mathrm{~B}$ \\
\hline Pousio & $10,6 \mathrm{AB}$ & $2,5 \mathrm{~A}$ & $8,8 \mathrm{~A}$ & $1,2 \mathrm{~A}$ & $1,5 \mathrm{~A}$ & $1,0 \mathrm{~B}$ \\
\hline
\end{tabular}

${ }^{1}$ Médias seguidas de mesma letra, maiúscula na coluna, não diferem entre si $(\mathrm{p}<0,05)$ pelo teste de Tukey.

2010), reduzindo a necessidade de aplicações de $\mathrm{N}$.

Além disso, essa família de plantas possui baixa relação $\mathrm{C} / \mathrm{N}$ em sua constituição, facilitando a mineralização do $\mathrm{N}$ e, consequentemente, sua liberação mais rápida às plantas.
As quantidades acumuladas dos macronutrientes nas espigas das plantas de milho não foram afetadas pelas plantas de cobertura cultivadas anteriormente à cultura do milho (Tabela 10). Baseandose no presente estudo, pode-se supor que a pouca

TABELA 10. Quantidades de macronutrientes acumuladas nas espigas das plantas de milho, em função das plantas de cobertura.

\begin{tabular}{|c|c|c|c|c|c|c|}
\hline Tratamenta & $\mathrm{N}$ & $P$ & K & $\mathrm{Ca}$ & $\mathrm{Mg}$ & $\mathrm{S}$ \\
\hline Aveia & $27,8 \mathrm{~A}$ & $8,7 \mathrm{~A}$ & $27,5 \mathrm{~A}$ & $3,7 \mathrm{~A}$ & $4,5 \mathrm{~A}$ & $3,2 \mathrm{~A}$ \\
\hline Braquiária decumbens & $36,1 \mathrm{~A}$ & $9,0 \mathrm{~A}$ & $30,4 \mathrm{~A}$ & $3,7 \mathrm{~A}$ & $4,7 \mathrm{~A}$ & $3,5 \mathrm{~A}$ \\
\hline Braquiária ruziziensis & $21,7 \mathrm{~A}$ & $4,7 \mathrm{~A}$ & $18,4 \mathrm{~A}$ & $2,2 \mathrm{~A}$ & $2,5 \mathrm{~A}$ & $2,1 \mathrm{~A}$ \\
\hline Crotalária juncea & $20,9 \mathrm{~A}$ & $4,0 \mathrm{~A}$ & $16,1 \mathrm{~A}$ & $2,2 \mathrm{~A}$ & $2,3 \mathrm{~A}$ & $1,8 \mathrm{~A}$ \\
\hline Girassol & $29,0 \mathrm{~A}$ & $6,1 \mathrm{~A}$ & $21,0 \mathrm{~A}$ & $2,8 \mathrm{~A}$ & $3,5 \mathrm{~A}$ & $2,5 \mathrm{~A}$ \\
\hline Nabo forrageiro & $41,9 \mathrm{~A}$ & $11,7 \mathrm{~A}$ & $34,0 \mathrm{~A}$ & $4,3 \mathrm{~A}$ & $6,7 \mathrm{~A}$ & $4,2 \mathrm{~A}$ \\
\hline Milheto ADR 500 & $22,4 \mathrm{~A}$ & $4,9 \mathrm{~A}$ & $17,9 \mathrm{~A}$ & $2,6 \mathrm{~A}$ & $3,0 \mathrm{~A}$ & $2,2 \mathrm{~A}$ \\
\hline Tremoço & $24,5 \mathrm{~A}$ & $4,5 \mathrm{~A}$ & $19,8 \mathrm{~A}$ & $2,9 \mathrm{~A}$ & $3,1 \mathrm{~A}$ & $2,2 \mathrm{~A}$ \\
\hline Pousio & $28,0 \mathrm{~A}$ & $6,9 \mathrm{~A}$ & $23,4 \mathrm{~A}$ & $3,0 \mathrm{~A}$ & $4,2 \mathrm{~A}$ & $2,8 \mathrm{~A}$ \\
\hline
\end{tabular}

${ }^{1}$ Médias seguidas de mesma letra, maiúscula na coluna, não diferem entre si $(\mathrm{p}<0,05)$ pelo teste de Tukey. 
variação ocorrida nas quantidades acumuladas de nutrientes nas diferentes partes das plantas de milho, em função da cultura anterior, esteja relacionada com os problemas climáticos durante a safra do milho.

As quantidades acumuladas de $\mathrm{N}, \mathrm{P}, \mathrm{K}$ e $\mathrm{Mg}$ na parte aérea das plantas de milho não variaram com as plantas de cobertura, com exceção do $\mathrm{Ca}$ e do $\mathrm{S}$ (Tabela 11). É possível que essa baixa variação ocorrida esteja relacionada com a pouca variação nas concentrações foliares de nutrientes nas diferentes partes das plantas de milho (Tabelas 5, 7 e 9) e na ausência de resposta na produtividade de MS das plantas de milho (Tabela 4).

Com exceção do $\mathrm{K}$ e do $\mathrm{Mg}$, as quantidades acumuladas de N, P, K, Ca e Mg observadas nesse experimento para se produzir $10,5 \mathrm{t} \mathrm{ha}^{-1}$, na média dos tratamentos, são semelhantes às descritas por Coelho e França (1995), respectivamente de $115,15,169,35$ e $26 \mathrm{~kg} \mathrm{ha}^{-1}$ para uma produtividade de MS da parte aérea do milho de 11,6 t ha-1.
Ressalta-se que a produtividade média de silagem de milho dos produtores da região Central de Minas Gerais tem se situado entre 10 a $15 \mathrm{t} \mathrm{ha}^{-1}$ de MS, dependendo das condições climáticas e do manejo. Dessa forma, esses números podem contribuir para estudos voltados para programas de reposição de nutrientes na região.

\section{Conclusões}

A produtividade de MS da parte aérea do milho não foi modificada pelas plantas de cobertura. Com pequenas exceções, as concentrações dos macronutrientes nas plantas de milho não variaram devido aos tratamentos. Por sua vez, as quantidades totais de $\mathrm{Ca}$ e de $\mathrm{S}$ nas das plantas de milho foram modificadas. As quantidades acumuladas de macronutrientes nas espigas também não foram afetadas pelos tratamentos, com exceção das quantidades de $\mathrm{P}$ e de Ca nas folhas e no colmo.

TABELA 11. Acúmulo de macronutrientes na parte aérea (total) da planta de milho, em função das plantas de cobertura.

\begin{tabular}{lcccccc}
\hline \multicolumn{1}{c}{ Tratamento } & $\mathrm{N}$ & $\mathrm{P}$ & $\mathrm{K}$ & $\mathrm{Ca}$ & $\mathrm{Mg}$ & $\mathrm{S}$ \\
& --------------------- \\
\hline Aveia & $119,2 \mathrm{~A}$ & $18,1 \mathrm{~A}$ & $90,9 \mathrm{~A}$ & $40,8 \mathrm{AB}$ & $15,7 \mathrm{~A}$ & $11,5 \mathrm{AB}$ \\
Braquiária decumbens & $136,9 \mathrm{~A}$ & $19,2 \mathrm{~A}$ & $109,3 \mathrm{~A}$ & $40,6 \mathrm{AB}$ & $16,8 \mathrm{~A}$ & $11,9 \mathrm{AB}$ \\
Braquiária ruziziensis & $104,6 \mathrm{~A}$ & $13,7 \mathrm{~A}$ & $77,6 \mathrm{~A}$ & $31,2 \mathrm{~B}$ & $12,0 \mathrm{~A}$ & $8,8 \mathrm{~B}$ \\
Crotalária juncea & $114,4 \mathrm{~A}$ & $14,5 \mathrm{~A}$ & $69,7 \mathrm{~A}$ & $36,5 \mathrm{AB}$ & $14,1 \mathrm{~A}$ & $9,2 \mathrm{AB}$ \\
Girassol & $132,1 \mathrm{~A}$ & $17,0 \mathrm{~A}$ & $80,2 \mathrm{~A}$ & $42,7 \mathrm{AB}$ & $15,1 \mathrm{~A}$ & $11,7 \mathrm{AB}$ \\
Nabo forrageiro & $160,2 \mathrm{~A}$ & $24,4 \mathrm{~A}$ & $120,5 \mathrm{~A}$ & $51,9 \mathrm{~A}$ & $21,7 \mathrm{~A}$ & $15,0 \mathrm{~A}$ \\
Milheto ADR 500 & $106,7 \mathrm{~A}$ & $14,4 \mathrm{~A}$ & $71,6 \mathrm{~A}$ & $36,3 \mathrm{AB}$ & $12,8 \mathrm{~A}$ & $9,6 \mathrm{AB}$ \\
Tremoço & $152,8 \mathrm{~A}$ & $20,0 \mathrm{~A}$ & $96,3 \mathrm{~A}$ & $55,3 \mathrm{~A}$ & $18,8 \mathrm{~A}$ & $13,5 \mathrm{AB}$ \\
Pousio & $127,1 \mathrm{~A}$ & $17,4 \mathrm{~A}$ & $84,8 \mathrm{~A}$ & $41,0 \mathrm{AB}$ & $17,3 \mathrm{~A}$ & $11,4 \mathrm{AB}$ \\
\hline Média & 114,3 & 15,4 & 79,4 & 38,10 & 14,20 & 10,30 \\
\hline
\end{tabular}

${ }^{1}$ Médias seguidas de mesma letra, maiúscula na coluna, não diferem entre si $(\mathrm{p}<0,05)$ pelo teste de Tukey. 


\section{Agradecimentos}

À Fundação Agrisus / Agricultura Sustentável e à Fapemig, pelo apoio financeiro para o desenvolvimento dos trabalhos.

\section{Referências}

ALVARENGA, R. C.; CABEZAS, W. A. L.; CRUZ, J. C.; SANTANA, D. P. Plantas de cobertura de solo para sistema plantio direto. Informe Agropecuário, Belo Horizonte, v. 22, p. 2536, 2001.

BORKERT, C. M.; GAUDÊNCIO, C. A.; PEREIRA, J. E.; PEREIRA, L. R.; OLIVEIRA JÚNIOR, A. Nutrientes minerais na biomassa da parte aérea em culturas de cobertura do solo. Pesquisa Agropecuária Brasileira, Brasília, DF, v. 38, p. 143-153, 2003.

CALEGARI, A. Espécies para cobertura de solo. In: DAROLT, M. R. (Coord.). Plantio direto: pequena propriedade sustentável. Londrina: IAPAR, 1998. p. 65-94. (IAPAR. Circular, 101).

CAMARGO, R.; PIZA, R. J. Produção de biomassa de plantas de cobertura e efeitos na cultura do milho sob sistema plantio direto no município de passos, MG. Bioscience Journal, Uberlândia, v. 23, p. 76-80, 2007.

CARVALHO, M.A.C.; SORATTO, R. P.; ATHAYDE, M. L. F.; ARF, O.; SÁ, M. E. Produtividade do milho em sucessão a adubos verdes no sistema de plantio direto e convencional. Pesquisa Agropecuária Brasileira, Brasília, DF, v. 39, p. 47-53, 2004.

COELHO A. M.; FRANÇA, G. E. Seja doutor no seu milho: nutrição e adubação. 2 . ed. ampl. Piracicaba: POTAFOS, 1995. 24 p. (POTAFOS. Arquivo do agrônomo, 2).

CRUSCIOL, C. A. C.; COTTICA, R. L.; LIMA, E. V.; ANDREOTTI, M. MORO; E. MARCON, E. Persistência de palhada e liberação de nutrientes do nabo forrageiro no plantio direto. Pesquisa Agropecuária Brasileira, Brasília, DF, v. 40, p. 161-168, 2005.

DERPSCH, R.; CALEGARI, A. Plantas para adubação verde de inverno. Londrina: IAPAR, 1992. 80 p. (IAPAR. Circular, 73).

GONÇAlVES, C. N.; CERETTA, C. A. Plantas de cobertura do solo antecedendo o milho e seu efeito sobre o carbono orgânico do solo, sob plantio direto. Revista Brasileira de Ciência do Solo, Campinas, v. 23, p. 304-313, 1999.

HEINZMANN, F. X. Resíduos culturais de inverno e assimilação de nitrogênio por culturas de verão. Pesquisa Agropecuária Brasileira, Brasília, DF, v.20, p.1021-1030, 1985.

MALAVOLTA, E.; VITTI, G. C.; OLIVEIRA, S. A. Avaliação do estado nutricional das plantas: princípios e aplicações. 2. ed. Piracicaba: Associação Brasileira para a Pesquisa da Potassa e do Fosfato, 1997. 319 p.

NUNES, U. R.; ANDRADE JÚNIOR, V. C.; SILVA, E. B.; SANTOS, N. F.; COSTA, H. A. O.; FERREIRA, C. A. Produção de palhada de plantas de cobertura e rendimento do feijão em plantio direto. Pesquisa Agropecuária Brasileira, Brasília, DF, v. 41, p. 943-948, 2006.

OLIVEIRA, T. K.; CARVALHO, G. J.; MORAES, R. N. S. Plantas de cobertura e seus efeitos sobre o feijoeiro em plantio direto. Pesquisa Agropecuária Brasileira, Brasília, DF, v. 37, p. 1079-1087, 2002. 
PERIN, A.; SANTOS, R. H. S.; CABALLERO, S. S. U.; GUERRA, J. G. M.; GUSMÃO, L. A. Acúmulo e liberação de $\mathrm{P}, \mathrm{K}, \mathrm{Ca}$ e $\mathrm{Mg}$ em crotalária e milheto solteiros e consorciados. Revista Ceres, Viçosa, MG, v. 57, p. 274-281, 2010.

RHEINHEIMER， D. S.; ALVAREZ， J. W. R.; OSORIO FILHO, B. D.; SILVA, L. S.; BORTOLUZZI, E. C. Resposta de culturas à aplicação de enxofre e a teores de sulfato num solo de textura arenosa sob plantio direto. Ciência Rural, Santa Maria, v. 35, 2005.

TEIXEIRA, C. M.; CARVALHO, G. J. C.; FURTINI NETO, A. E.; ANDRADE, M. J. B.; MARQUES, E. L. S. Produção de biomassa e teor de macronutrientes do milheto, feijãode-porco e guandu-anão em cultivo solteiro e consorciado. Ciência e Agrotecnologia,
Lavras, v. 29, p. 93-99, 2005.

TORRES, J. L. R.; PEREIRA, M. G.; ANDRIOLI, I.; POLIDORO, J. C.; FABIAN, A. J. Decomposição e liberação de nitrogênio de resíduos culturais de plantas de cobertura em um solo de cerrado. Revista Brasileira de Ciência do Solo, Campinas, v. 29, p. 609-618, 2005.

TORRES, J. L. R.; PEREIRA, M. G.; FABIAN, A. J. Produção de fitomassa por plantas de cobertura e mineralização de seus resíduos em plantio direto. Pesquisa Agropecuária Brasileira, Brasília, DF, v. 43, p. 421-428, 2008.

TORRES, J. L. R.; PEREIRA, M. G. Dinâmica do potássio nos resíduos vegetais de plantas de cobertura no cerrado. Revista Brasileira de Ciência do Solo, Campinas, v. 32, p. 1609$1618,2008$. 